REVISTA DE ESTUDOS EM ARTES CÊNICAS

E-ISSN 2358.6958

\title{
Altamira 2042: \\ Performance feminista e o antropoceno
}

\author{
Ana Bernstein
}

\section{Para citar este artigo:}

BERNSTEIN, Ana. Altamira 2042. Performance feminista e o antropoceno. Urdimento - Revista de Estudos em Artes Cênicas, Florianópolis, v. 3, n. 42, dez. 2021.

doi DOl: http:/dx.doi.org/10.5965/1414573103422021e0202

Este artigo passou pelo Plagiarism Detection Software| iThenticate 


\begin{abstract}
Resumo
Este ensaio trata da crise climática através da discussão de Altamira 2042, uma performance-instalação multimídia de Gabriela Carneiro da Cunha, que aborda as consequências sociais, culturais e ambientais da construção da usina hidrelétrica de Belo Monte, responsável por um dos piores ecocídios do século XXI. A distopia de Belo Monte evidencia o conflito entre os interesses do capital global, as forças do "progresso" e a sobrevivência da população local e suas organizações sociais, conhecimentos e tradições; entre a tecnologia instrumental da modernidade e suas tecnologias antigas. O ensaio debruça-se sobre a questão de como as performances feministas podem responder ao espectro da extinção em massa e à crise da mudança climática.
\end{abstract}

Palavras-chave: Altamira 2042. Performance. Feminismo. Antropoceno. Mudança climática.

\title{
Altamira 2042: Feminist performance and the anthropocene
}

\begin{abstract}
This essay deals with climate crisis through the discussion of Altamira 2042, a multimedia performance-installation by Gabriela Carneiro da Cunha, which addresses the social, cultural and environmental consequences of the construction of the Belo Monte hydroelectric plant, responsible for one of the worst ecocides of the 21st century. Belo Monte's dystopia highlights the conflict between the interests of global capital, the forces of "progress," and the survival of the local population and their social organizations, knowledge and traditions; between modernity's instrumental technology and their ancient technologies. The essay focuses on how feminist performances can respond to the specter of mass extinction and climate change.
\end{abstract}

Keywords: Altamira 2042. Performance. Feminism. Anthropocene. Climate Change.

${ }^{1}$ Doutora em Estudos da Performance (New York University). Mestre em História Social da Cultura (PUC-RJ). Bacharel em Artes Cênicas (Unirio). Professora de História da Arte, Estética e Teoria do Teatro e Estudos da Performance da Universidade Federal do Estado do Rio de Janeiro (Unirio). ana.bernstein@unirio.br

(9) http://lattes.cnpq.br/7537528020648098 (iD https://orcid.org/0000-0002-0927-4572 


\section{Altamira 2042: Performance feminista y antropoceno}

\section{Resumen}

Este ensayo aborda la crisis climática, por medio de la discusión de Altamira 2042, una performance-instalación de Gabriela Carneiro da Cunha, que trata las consecuencias sociales, culturales y ambientales de la construcción de la central hidroeléctrica de Belo Monte, responsable por uno de los peores ecocidios del siglo XXI. La distopía de Belo Monte pone en evidencia el conflicto de intereses del capital global y la sobrevivencia de la población local y sus organizaciones sociales, conocimientos y tradiciones; entre la tecnología instrumental de la modernidad y sus tecnologías antiguas. El ensayo se centra en cómo las performances feministas pueden responder al espectro de la extinción en masa y a las crisis de cambio climático.

Palabras clave: Altamira 2042. Performance. Feminismo. Antropoceno. Cambio climático. 
They paved paradise and put up a parking lot. (Joni Mitchell)

Why can we imagine the ending of the world, yet not the ending of colonialism? (Indigenous Anti-Futurist Manifesto)

A violência contra os descendentes dos milhões de indígenas do Brasil que aqui habitavam quando da chegada dos colonizadores e que foram sistematicamente dizimados durante a colonização, atingiu níveis sem precedentes nos últimos anos, especialmente desde o surgimento da nova pandemia de coronavírus. Os cerca de 900.000 sobreviventes do genocídio colonial, agora mais vulneráveis do que nunca, encontram-se sob ataque do governo brasileiro. Como afirma o antropólogo Eduardo Viveiros de Castro, estamos testemunhando "a ofensiva final contra os povos indígenas" (Viveiros de Castro, 2019), a conclusão de uma campanha de genocídio que teve início em 1500. A pandemia de Covid-19 agravou uma situação já terrível ao proporcionar ao governo de Jair Bolsonaro novas oportunidades para pôr em perigo as comunidades indígenas. Enquanto a pandemia assola a vida dos brasileiros, o acesso a assistência médica, medicamentos, alimentos e água potável tem sido sistematicamente negado a esta população altamente vulnerável. O governo não hesitou, entretanto, em fornecer aos indígenas enormes quantidades de hidroxicloroquina, uma droga que se mostrou ineficaz para o tratamento da Covid19 e foi desacreditada pela Organização Mundial da Saúde - em uma ação que lembra a biopolítica colonial de distribuir roupas infectadas com varíola aos povos nativos. As terras indígenas têm sido atacadas por mineiros, madeireiros e invasores de terras fortemente armados, incentivados pelo ex-Ministro do Meio Ambiente de Bolsonaro, Ricardo Salles, ele próprio sob investigação por tráfico de madeira amazônica. Juntamente com esta violência sistemática, estamos testemunhando também a destruição acelerada de biomas preciosos insubstituíveis, com consequências catastróficas para o planeta.

É somente graças às sociedades indígenas, consideradas pelo Ocidente como "primitivas", que a Amazônia ainda não foi totalmente destruída. Os cientistas nos alertaram que a maior floresta tropical do mundo está se aproximando de um 
ponto de ruptura e provavelmente experimentará um processo de desertificação. Enquanto a crescente consciência dos danos irreversíveis ao meio ambiente causados pelas atividades humanas nos obriga a enfrentar a perspectiva do fim do mundo, o fato é que para os ameríndios, o mundo acabou em 1500, após seus primeiros encontros com os europeus.

Em seu ensaio A questão da técnica, de 1954, Martin Heidegger argumenta que a modernidade é definida por sua razão instrumental e tecnologia. Na Grécia antiga, entretanto, technē era inseparável da arte e do conhecimento - assim, a poiesis era um meio de "revelar aquilo que não se apresenta e ainda não se encontra aqui diante de nós"2. Para Heidegger, o conceito moderno de tecnologia visa regular, proteger e controlar a natureza, instrumentalmente concebida como uma fonte ilimitada de energia e recursos a serem explorados e armazenados. À medida que os seres humanos se dissociaram dos não-humanos e começaram a se ver como superiores e extraordinários, afirmando uma forma de "supremacia da espécie", a natureza se tornou uma reserva permanente para seus propósitos. Além disso, conforme os humanos procuram satisfazer suas necessidades imediatas, eles colonizam, exploram, armazenam, transformam, distribuem e esgotam os recursos da Terra: "Em todos os lugares tudo é ordenado para ficar de prontidão, para estar imediatamente à mão, de fato, para ficar ali apenas para que possa estar de plantão para um novo pedido"3. Informados por esta visão instrumental, os seres humanos deixaram de ser agentes biológicos para se tornarem agentes geológicos (Chakrabarty, 2009). Ou, nas palavras de Eliane Brum, "os humanos deixam de apenas temer a catástrofe para se tornar a catástrofe" (Brum, 2014).

2 It reveals whatever does not bring itself forth and does not yet lie here before us (Heidegger, 1977 p.13). (Tradução nossa)

${ }^{3}$ Everywhere everything is ordered to stand by, to be immediately at hand, indeed to stand there just so that it may be on call for a further ordering. Whatever is ordered about in this way has its own standing (Heidegger, 1977, p.17). (Tradução nossa) 
A magnitude do impacto ambiental no planeta causado pela mentalidade extrativista que caracteriza a relação humana com a natureza (Klein, 2019), erroneamente concebida como passiva e estável, resultou em extensos danos à biosfera, levando vários cientistas a designar a era geológica atual como o Antropoceno. O termo, popularizado em 2000 por Paul Crutzen, e rapidamente adotado por muitos estudiosos, não escapou à controvérsia, justamente por seu foco na palavra Antropoceno, reforçando a ideia de uma Era do Homem. Os críticos do termo - e da suposição de que um "bom Antropoceno" é possível e até desejável - propuseram outras designações como Capitaloceno (Andreas Malm, Jason W. Moore), Plantationocene, Chthulucene (Donna Haraway), e Gaia (Bruno Latour, Isabelle Stengers). Igualmente controversa é a datação desta nova era geológica. Enquanto Crutzen e Stoermer a associam à Revolução Industrial no século XIX, outros estudiosos afirmam que ela remonta ao início da agricultura, enquanto alguns apontam para o período da Segunda Guerra Mundial e o desenvolvimento da bomba atômica. Autores como Moore, Haraway e Viveiros de Castro e Danowski a datam do início da colonização europeia e da transição do feudalismo para o capitalismo. Como argumentam Viveiros de Castro e Danowski (2015, p.141):

O genocídio dos povos ameríndios - o fim do mundo para eles - foi o começo do mundo moderno na Europa: sem a espoliação da América, a Europa jamais teria deixado de ser um fundo de quintal da Eurásia, continente que abrigava, durante a Idade Média", civilizações imensamente mais ricas do que as europeias (Bizâncio, China, Índia, o mundo árabe). Sem o saque das Américas, não haveria capitalismo, nem, mais tarde, revolução industrial, talvez nem mesmo, portanto, o Antropoceno.

Os estudiosos que usam o termo Capitaloceno enfatizam o papel do capitalismo na criação e no agravamento da atual crise ecológica. Para eles, a nossa não é a "Era do Homem", é a Era do Capital. Como dizem Moore e Patel, "não é apenas um comportamento humano natural, mas uma interação específica entre o homem e o mundo biológico e físico que nos trouxe até este ponto". ${ }^{4}$ Nomear esta nova era geológica de Capitaloceno é levar "a sério o capitalismo, entendendo-o não apenas como um sistema econômico, mas como uma forma 
de organizar as relações entre os seres humanos e o resto da natureza. ${ }^{5}$ (grifo nosso) Para ter sucesso, o capitalismo precisa transformar humanos e nãohumanos em objetos, de preferência baratos, que mais rapidamente geram excedentes e acumulações.

A ideia da natureza com N maiúsculo, esse algo exterior do qual os humanos são hiper-separados, para usar a expressão de Valerie Plumwood, coincide com a colonização europeia e o início do capitalismo. Esta ideia de Natureza incluía não apenas terras, rios, fauna e flora, mas também aqueles vistos como sub-humanos, inferiores, ou primitivos - mulheres, indígenas e negros - encarados como recursos baratos e fontes de mão-de-obra livre. Claramente, essa noção de Antropos não diz respeito a um grupo homogêneo de humanos, como a colonização no passado e as políticas ne[cr]oliberais de hoje tornam evidente. Algumas vidas ainda importam mais do que outras.

A implementação global das políticas neoliberais do capitalismo tardio, que promovem o livre mercado e a privatização de "bens" essenciais como água e energia, bem como o desmantelamento dos direitos dos trabalhadores, juntamente com o corte dos gastos públicos com saúde, moradia, educação e transporte público, aumentaram a precariedade daqueles cujas vidas são menos importantes do que os interesses das grandes corporações (não é à toa que nos EUA estas possuem os mesmos direitos legais que as pessoas). Isso se tornou evidente com a pandemia da COVID-19, quando empresas obtiveram lucros astronômicos enquanto quase quatro milhões de vidas foram perdidas no mundo inteiro e a situação das populações que já sofriam de pobreza, desemprego, discriminação sistemática, racismo, conflitos fundiários, falta de programas de assistência social e, em alguns casos, guerra e migração forçada, foi ainda mais exacerbada.

Nesta era de extrema desigualdade e discriminação, a teoria e a prática feministas são ferramentas essenciais para mudar nossos modos de pensar e agir antropocêntrico, capitalista e colonialista. Muito antes da formação do consenso

${ }^{5}$ Using this name means taking capitalism seriously, understanding it not just as an economic system but as a way of organizing the relations between humans and the rest of nature (Patel and Moore, 2017, p.14-15). (Tradução nossa) 
em torno de uma nova era geológica, as ecofeministas já questionavam a hiper separação entre o Homem e a Natureza (Plumwood) e abordavam o impacto das atividades humanas sobre outras espécies e ambientes. As feministas criticaram a ideia da Natureza como passiva, inferior e feminizada por estar ancorada em uma lógica de dualismos hierárquicos, e fizeram conexões entre os problemas ambientais e a justiça de gênero e racial. As práticas racistas ambientais, tais como o despejo de produtos industriais tóxicos, resíduos e contaminação da água, afetam desproporcionalmente as comunidades mais vulneráveis, geralmente constituídas por minorias raciais, de classe e de gênero.

Nas seções que se seguem, examino Altamira 2042, uma performance instalação multimídia de Gabriela Carneiro da Cunha, que aborda as consequências sociais, culturais e ambientais da construção da usina hidrelétrica de Belo Monte que desviou o curso do rio Xingu, um dos principais tributários da Amazônia no estado do Pará. A obra de Cunha é um exemplo de uma atuação feminista que confronta o espectro do colapso ecológico.

\section{(2) ()}

Inaugurada em 5 de maio de 2016, Belo Monte, localizada no primeiro território indígena demarcado no Brasil, é a quarta maior represa hidrelétrica do mundo. Para construí-la, o Estado forçou o deslocamento de diversas comunidades indígenas e populações tradicionais. O projeto foi concebido pelo regime ditatorial civil-militar e data de 1975. Na época, foi recebido com forte resistência de grupos indígenas e de direitos humanos, cujas ações impediram sua construção até 2003. Durante a ditadura militar, a política delineada para a Amazônia foi a de "fomentar o progresso" na região. Isso significou assentar, promover a migração para ocupar e desenvolver a terra como se esta fosse despovoada e sem uso. Do mesmo modo como os europeus viram as Américas como terra nullios, ou seja, terra de ninguém, e se apossaram das terras em nome de seus governos, o governo via a Amazônia como desocupada, improdutiva, desconsiderando as populações indígenas e tradicionais como os ribeirinhos e quilombolas que ali viviam. Assim, o governo militar deu posse de terras aos 
agricultores, ergueu barragens e construiu a Rodovia Transamazônica, que corta milhares de quilômetros de floresta tropical, exterminando e deslocando nações indígenas inteiras no processo.

Uma das maiores bacias hidrográficas do mundo, a Amazônia tem sido cobiçada por várias administrações e corporações transnacionais como fonte de energia hidrelétrica. Ao longo dos anos, as políticas de conservação dos recursos naturais da Amazônia não se diferenciaram significativamente das do regime ditatorial militar (embora tenham se agravado drasticamente sob o governo Bolsonaro). Ironicamente, foi durante os governos democraticamente eleitos do presidente Luís Inácio Lula da Silva e Dilma Rousseff, ambos membros do Partido dos Trabalhadores, que Belo Monte finalmente se concretizaria, apesar dos vários desafios legais das nações indígenas, de ribeirinhos, das agências ambientais locais e internacionais, e do próprio Ministério Público, numa clara violação dos direitos indígenas garantidos pela Constituição do país. Todos os estudos de impacto ambiental da barragem realizados nos últimos 30 anos denunciaram o projeto que devastaria o ecossistema do Xingu, um dos biomas mais ricos e diversificados do planeta, e deslocaria milhares de pessoas, destruindo seus meios de subsistência e tradições. Além disso, pesquisadores de energia observaram que a energia da barragem seria ineficiente devido à seca regional e sazonal, quando os níveis de água diminuem significativamente e parte das turbinas da barragem é paralisada (Brum, 2016).

A mentalidade desenvolvimentista e extrativista que impulsiona as políticas energéticas e de investimento do Brasil assume que a natureza fornece recursos ilimitados e está voltada para a implementação do agronegócio, da mineração e das indústrias madeireiras. Tais práticas expõem um processo de recolonização da natureza e dos povos indígenas incentivado pela agenda neoliberal do Estado. Como afirma Viveiros de Castro, é de fato um processo de auto-recolonização, no qual o país revive intencionalmente seu legado colonial e políticas para se tornar uma verdadeira plantação, ou seja, um "exportador de produtos primários para as metrópoles capitalistas. Estamos na mesma posição em que estávamos em 1500. É uma colônia de exportação de commodities" (Viveiros de Castro, 2019). 
A distopia de Belo Monte, produzida pela obsessão do capitalismo pelo "progresso" e pelo crescimento é o tema da performance instalação Altamira 2042 de Cunha, que estreou em 2019 na Mostra Internacional de Teatro de São Paulo (MIT-SP) e vem sendo apresentada no Brasil e no exterior.

O trabalho é resultado de três anos de pesquisa artística e faz parte de um projeto maior chamado Margens - Sobre Rios, Buiúnas e Vaga-lumes, durante o qual Cunha e seus/suas colaboradores/as se inseriram na cidade de Altamira, convivendo com os sobreviventes deste crime ecológico que é Belo Monte. Na apresentação, o rio Xingú figura como testemunha do desastre de Belo Monte. A performance cria "[u]ma polifonia de seres, línguas, sonoridades e perspectivas" de seres humanos e não-humanos que falam através de dispositivos tecnoxamânicos (caixas de som e pen drives) (Programa Altamira 2042). O espetáculo procura "deslocar os humanos do centro da narrativa. [...] torná-los ouvidos para escutar as vozes de todo o resto que existe. Nesse caso, os rios-testemunha, os povos-vagalumes e as mulheres buíunas" (Cunha).

Antes de entrar no espaço da performance, cada espectador responde a uma pergunta: rio ou rua? Rua é o que os moradores locais chamam a cidade. Então, ele/ela é levado para um lugar no interior da sala escura. Não há cadeiras, apenas algumas almofadas no chão. A performer coloca cuidadosamente na frente dos espectadores uma série de caixas de som que piscam aleatoriamente luzes coloridas. Uma paisagem sonora de floresta, rio, pássaros, insetos e sapos preenche lentamente o espaço. Escuridão, luzes e sons coloridos criam uma experiência sensorial, uma pausa bem-vinda da cidade movimentada que deixamos do lado de fora. Cunha movimenta-se pela sala, reordenando as caixas de som, ajustando volumes, ligando-os e desligando-os, reconfigurando continuamente o espaço. Lentamente, ruídos de máquinas, motosserras, carros e construção dominam a paisagem sonora, sobrecarregando a experiência sensorial do público. A rua oblitera o rio e o público é reduzido à sua própria miséria.

Além dessa abertura, a performance compõe-se de três partes: Dona Herondina, a narradora encantada das mulheres buíunas (definidas por Cunha como mulheres artistas das margens; mulheres que habitam as margens e o fundo do rio; e mulheres ativistas) tem corpo de mulher (o corpo da performer) e uma 
cabeça composta por duas caixas de som. A voz deste ser cibernético, uma figura simpoiética, pertence a Dona Raimunda, cuja família foi despejada e cuja casa e pertences foram queimados pela Norte Energia S.A., a empresa construtora da barragem. Enquanto ela conta a história da mulher-cobra, o espírito das águas, imagens do rio são projetadas nas paredes. As mulheres têm estado na vanguarda da luta contra Belo Monte, e Herondina/Raimunda é uma mulher guerreira. Ela testemunha, lembrando outras mulheres ativistas assassinadas defendendo a floresta, para as quais não houve justiça. "Eu sou a mata, a floresta / A floresta está viva como eu", diz ela, evocando o conceito de perspectivismo ameríndio de Tânia Stolze Lima e Viveiros de Castro, central para o projeto.

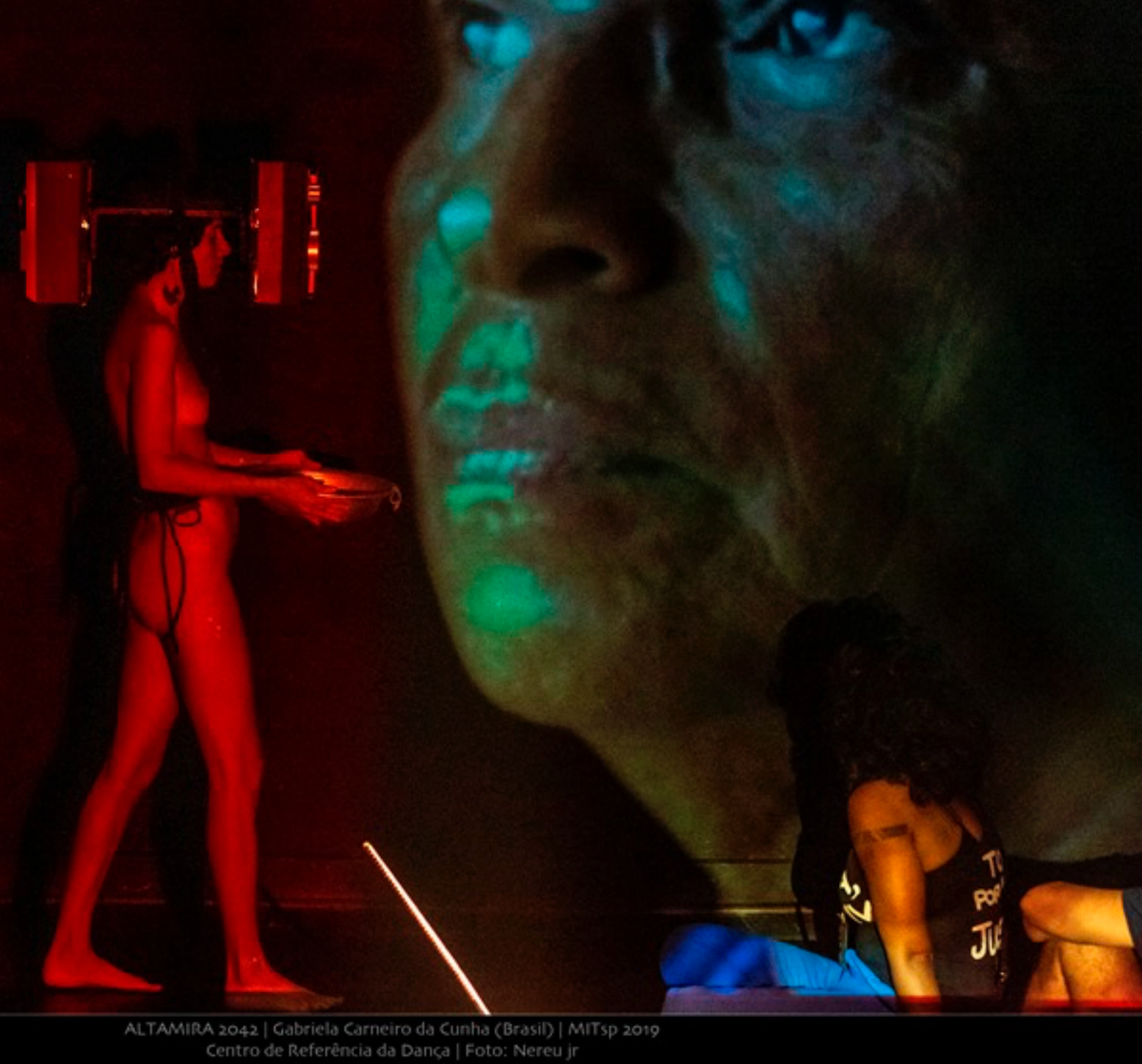


Ao contrário dos Antropos, os ameríndios (e a maioria dos povos indígenas do mundo) não se veem como diferentes dos não-humanos. Eles se veem como seres semelhantes aos animais, minerais e plantas. Eles "compartilham de uma concepção segundo a qual o mundo é composto por uma multiplicidade de pontos de vista: todos os existentes são centros potenciais de intencionalidade, que apreendem os demais existentes segundo suas próprias e respectivas características ou potências"(Viveiros de Castro, 2015, s./p.). Em outras palavras, para os ameríndios, todos os seres são pessoas (mas não humanos), eles compartilham a mesma "alma". Os animais percebem o mundo como as pessoas, mas como seus corpos são diferentes, eles percebem coisas diferentes. Esta diferença na percepção não é uma questão de fisiologia, como nota Viveiros de Castro, uma vez que o corpo é antes um "feixe de afetos e capacidades, e que é a origem do perspectivismo" (Viveiros de Castro, 2015, s./p.).

No mito da mulher-cobra, uma jovem mulher dá à luz a uma menina no rio e a abandona ali, morrendo de hemorragia logo em seguida. O bebê se transforma em uma cobra de rio e, em noites de lua cheia, se transmuta em uma jovem mulher em busca de parceiros sexuais. Sua "maldição" só terminará quando ela der à luz a uma criança. Esta parte da performance termina com uma cena de parto na qual Herondina, a mulher-sonora, dá à luz uma criança-sonora. Assistimos ao nascimento de uma cobra: com seu corpo preso a uma longa trilha de luzes serpentinas LED, esta techno-criatura simpoiética canta e realiza uma lenta coreografia de corpo e luz. 


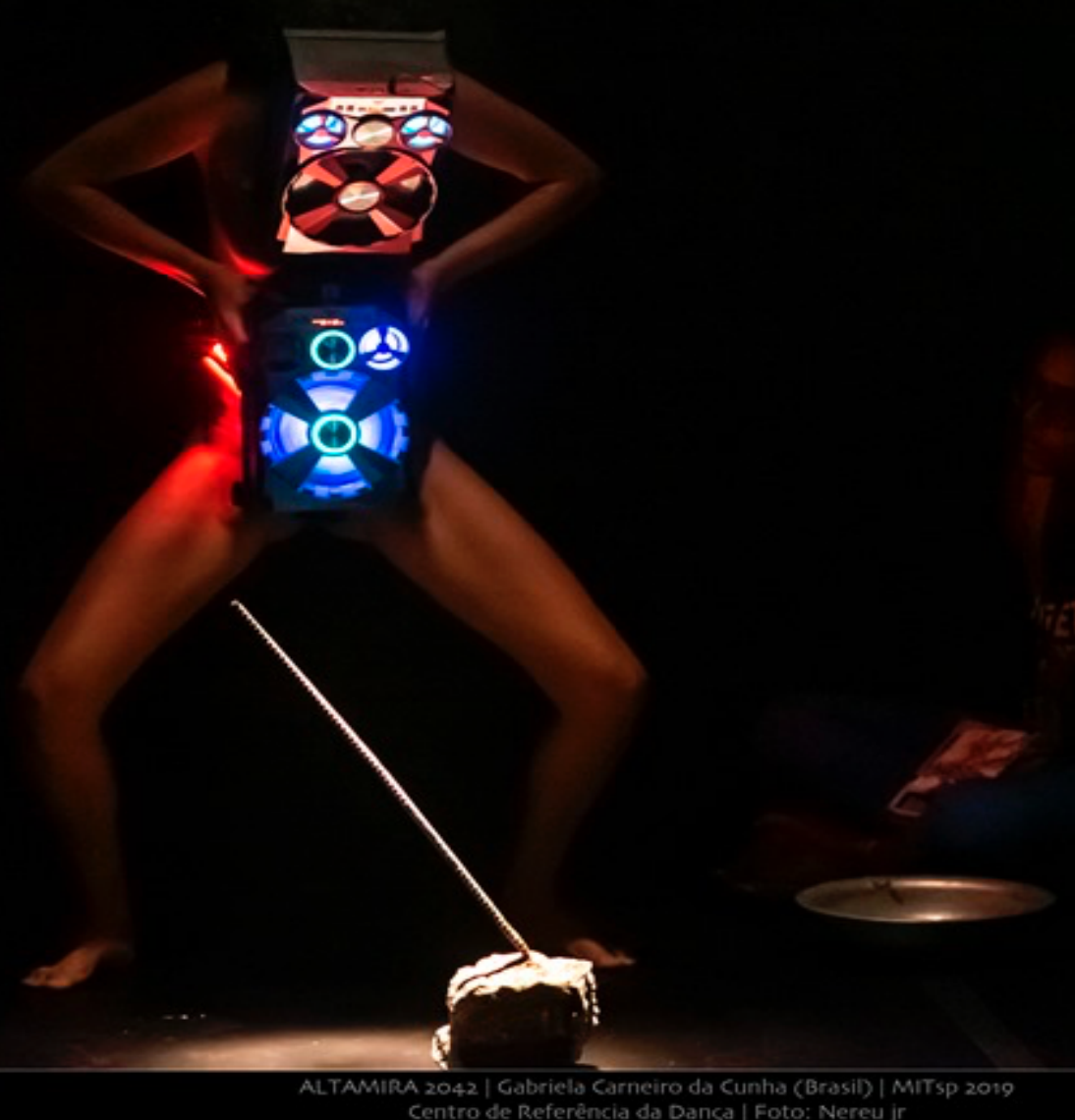

Seu Quebra Barragem, o narrador encantado dos rios-testemunhas, preside a segunda parte da performance. Ele é uma Grande Cobra Audiovisual, outro ser simpoiético, e seu corpo é um híbrido do próprio corpo da performer, uma caixa de som e cabeça de projetor de vídeo. Considero tanto Dona Herondina quanto Seu Quebra Barragens exemplos do que Haraway chama de "assemblages naturaisculturais”, um emaranhado simpoiético de criatura e tecnologia, uma entidade humana-não humana. É através dessa figura que ouvimos as vozes dos ribeirinhos expulsos das ilhas do Xingu, das nações Araweté e Juruna, de líderes do movimento Xingu Vivo, além das vozes da floresta, dos animais, da chuva e do próprio rio.

${ }^{6}$ naturalcultural assemblages (Haraway, 2016, p.38). (Tradução nossa) 
Vemos Altamira, uma cidade de mortos vivos, de pescadores sem peixe e de povos indígenas sem terra, água e alimentos nutritivos. Nos encontramos subitamente no epicentro de uma guerra global entre dois mundos. A Amazônia, centro do mundo, é o local onde se trava a batalha final. Ouvimos a voz de um homem velho que diz que o rio Xingú está morto: porque "ele não pode falar, o rio sofre em silêncio". Mas "se o rio pudesse falar, ele choraria".

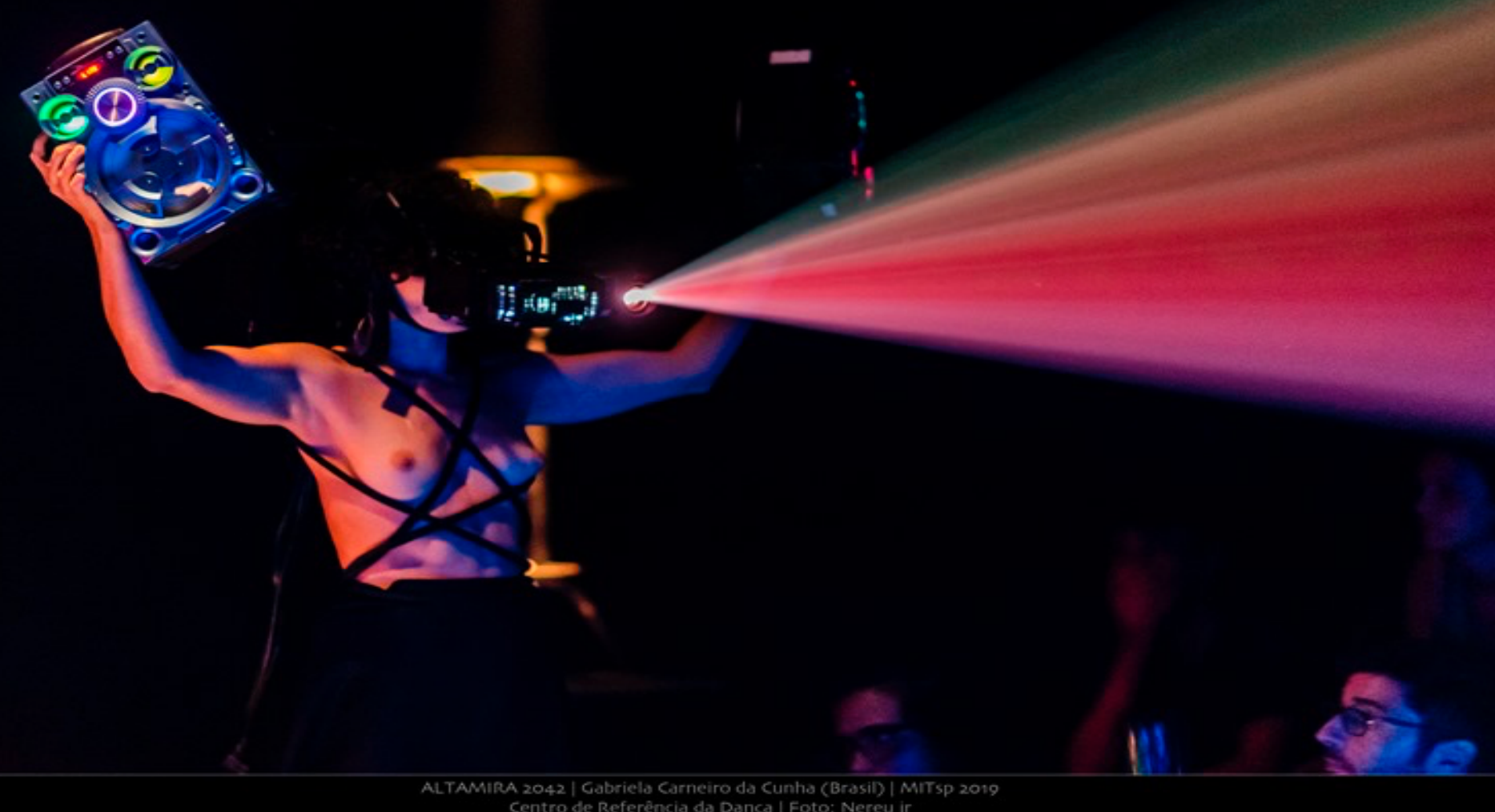

A guerra entre dois mundos constitui a terceira parte do espetáculo, intitulada Aliendígena. Nela, vemos o/a narrador/a encantado/a do povo vagalume, isto é, povos em risco de extinção mas cuja luz insiste em cintilar. O corpo do/a narrador/a é composto por instrumentos xamânicos como guizos e tambores. Se 
forem tocados em uníssono por todos, o corpo alienígena destruirá a represa no ano 2042.

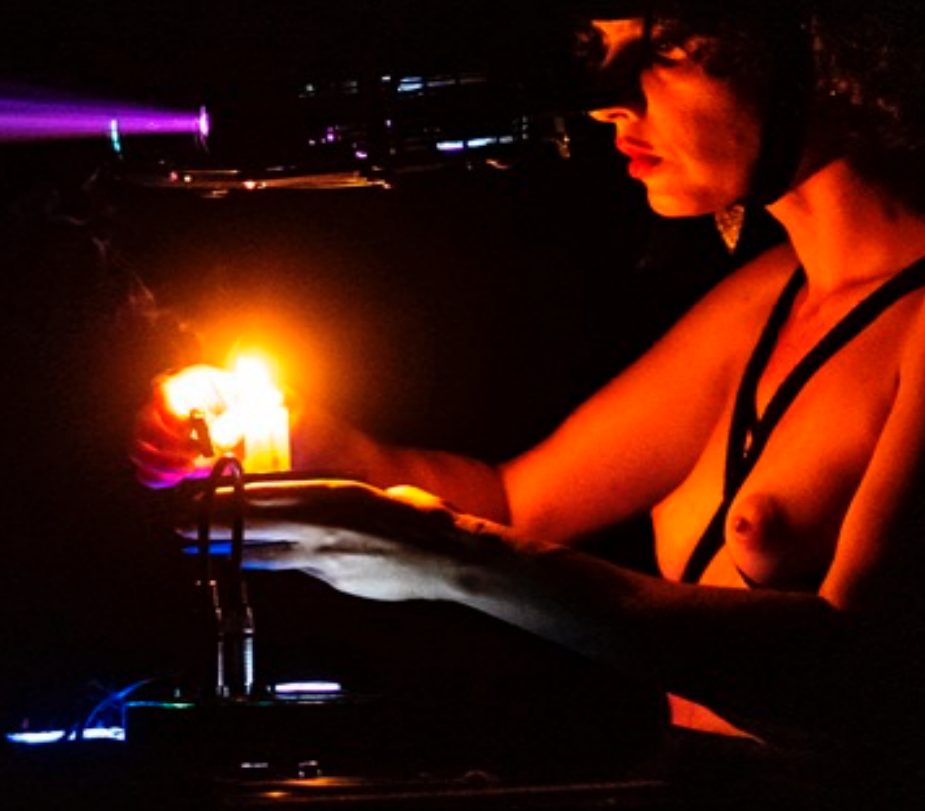

Esta parte começa como um filme de ficção científica ruim sobre uma nave espacial alienígena que aterrissa no rio Amazonas em 2015, carregando um grupo de pessoas conhecidas como Progressianos. Uma sensação de dejà vu se instala: já não vimos este filme em 1500? Os Progressianos são "um povo puro", cujo único objetivo é criar desertos, uma tarefa que requer o extermínio de todas as outras pessoas. Sua arma é a caneta. Com ela, podem matar milhões com um único golpe, sem necessidade de armas atômicas. Sua mitologia é a História. As imagens são agora projetadas também nos espectadores, estão enredadas em 
seus corpos. Em contraste com os progressianos, os aliendígenas são um povo misto, cuja missão é "amazonizar" o mundo. Suas ferramentas são canções, danças, linguagem e sonhos. Um ser aliendígena representa soma, em vez da subtração: ele/ela é vento e espírito, peixe e canoa, ele/ela é Terrano, rua, caracol e luz. A questão que ele/ela enfrenta é ser e estar, estar com os outros, semelhante aos outros.

A partir de sua assemblage de computador, teclado e luzes, o/a Aliendígena escreve a história dessa guerra final, projetada em feixes de luz por meio de seus olhos de vídeo. Mais tarde, ele/ela pega o martelo e o cinzel e retoma o trabalho simbólico de destruir a represa. O público gradualmente se junta ao/a aliendígena, criando uma assemblage nova e mais poderosa. Os sons do martelo e do cinzel tornam-se cada vez mais altos, mais ritmados. Outros membros da plateia tocam guizos e tambores. A performance se transforma lentamente em um ritual coletivo guiado pela performer/xamã. Na cena final, vemos a imagem de uma barragem rompida, seguida de torrentes de água que correm livremente.

É possivelmente um sonho, mas precisamos sonhar para produzir mudanças. Na experiência indígena, os sonhos não são apenas parte do sono, são o "exercício disciplinado" que orientam "nossas escolhas do dia a dia" (Krenak, 2020) Ou, como explica o xamã Yanomami Davi Kopenawa, o sonho é "nosso modo de estudar" (Kopenawa e Albert, 2010, p.462).

Em Staying With The Trouble, Haraway exorta as feministas a "exercer alta liderança em imaginação, teoria e ação"7. Para Cunha, a artista feminista também deve aprender a sonhar. Seus olhos e ouvidos devem morrer antes que ela aprenda a ver e ouvir outras pessoas e outros lugares, algo que aprendeu com o xamã Yanomami Kopenawa. Ela poderia então tornar-se semelhante ao xamã que ensina os outros a sonhar e ver seres, tempos e realidades diferentes (Cunha, Rios). 


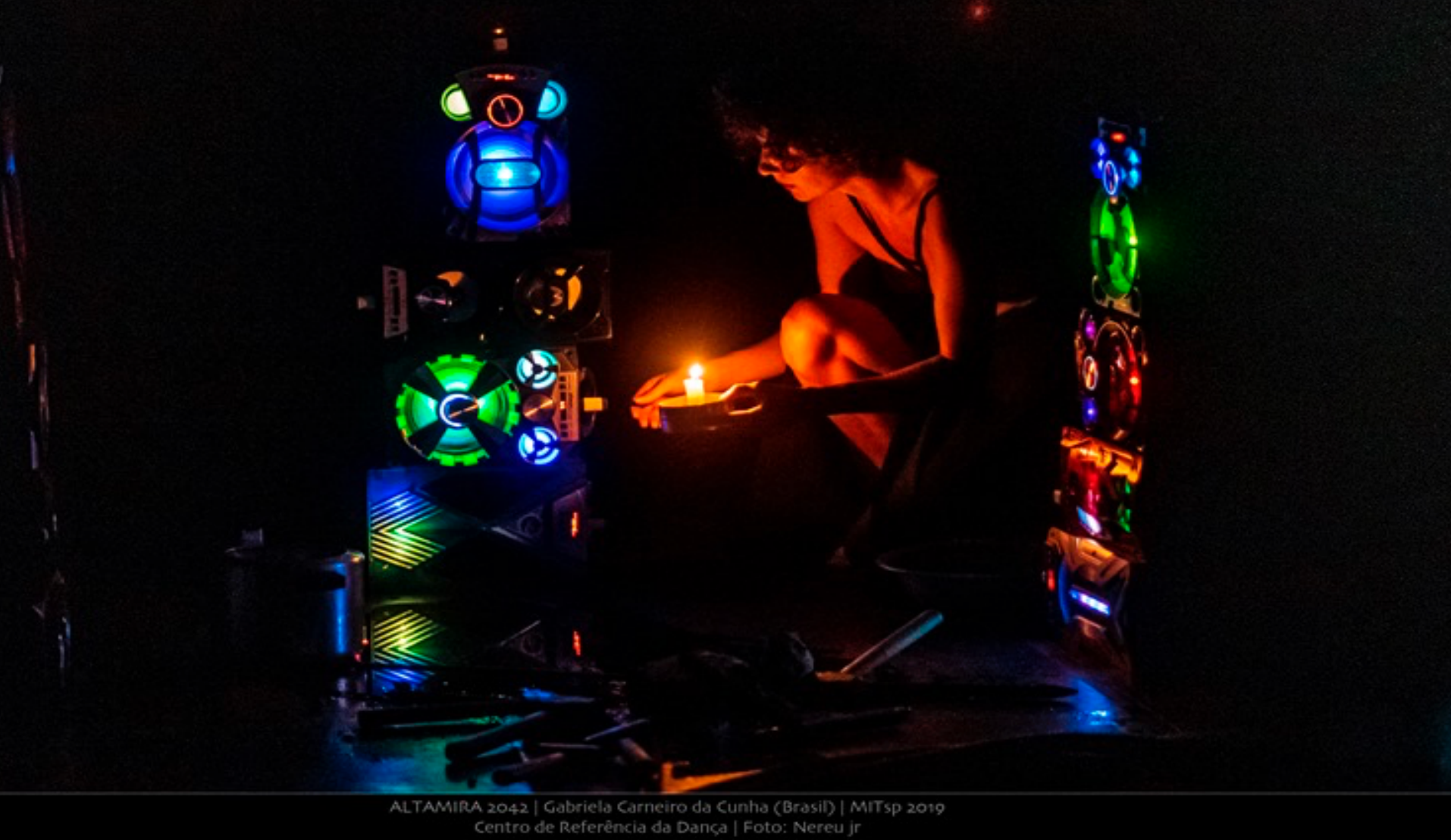

Como os seres simpoiéticos, conjuntos humanos-não humanos que defendem a floresta e as águas, devemos aprender a criar novas relações inter e entre espécies, novas alianças; devemos abrir nossos olhos e ouvidos para a polifonia de vozes e seres, formar parentesco com outros e pensar com nossos companheiros da Terra (Haraway). Devemos deslocar os seres humanos do centro da narrativa, substituindo uma lógica dualista por uma multiplicidade de perspectivas. Os povos indígenas podem nos ensinar "como viver melhor em um mundo pior" (Viveiros de Castro, 2014). Afinal, eles são "especialistas do fim do mundo", como diz Viveiros de Castro. Eles tiveram que aprender a viver em um mundo invadido e devastado pelos colonizadores brancos, e têm resistido à dominação por cinco séculos. Podemos aprender com eles como "repensar nossa 
relação com o mundo material” (Viveiros de Castro, 2014). São lições que devemos aprender se quisermos vencer a luta contra o capitalismo do desastre e o colonialismo e evitar uma catástrofe ecológica.

\section{() () ()}

Depois que todas as caixas de som com suas luzes são desligadas e a música diminui lentamente, resta apenas uma luz de vela, que Cunha apaga com um sopro.

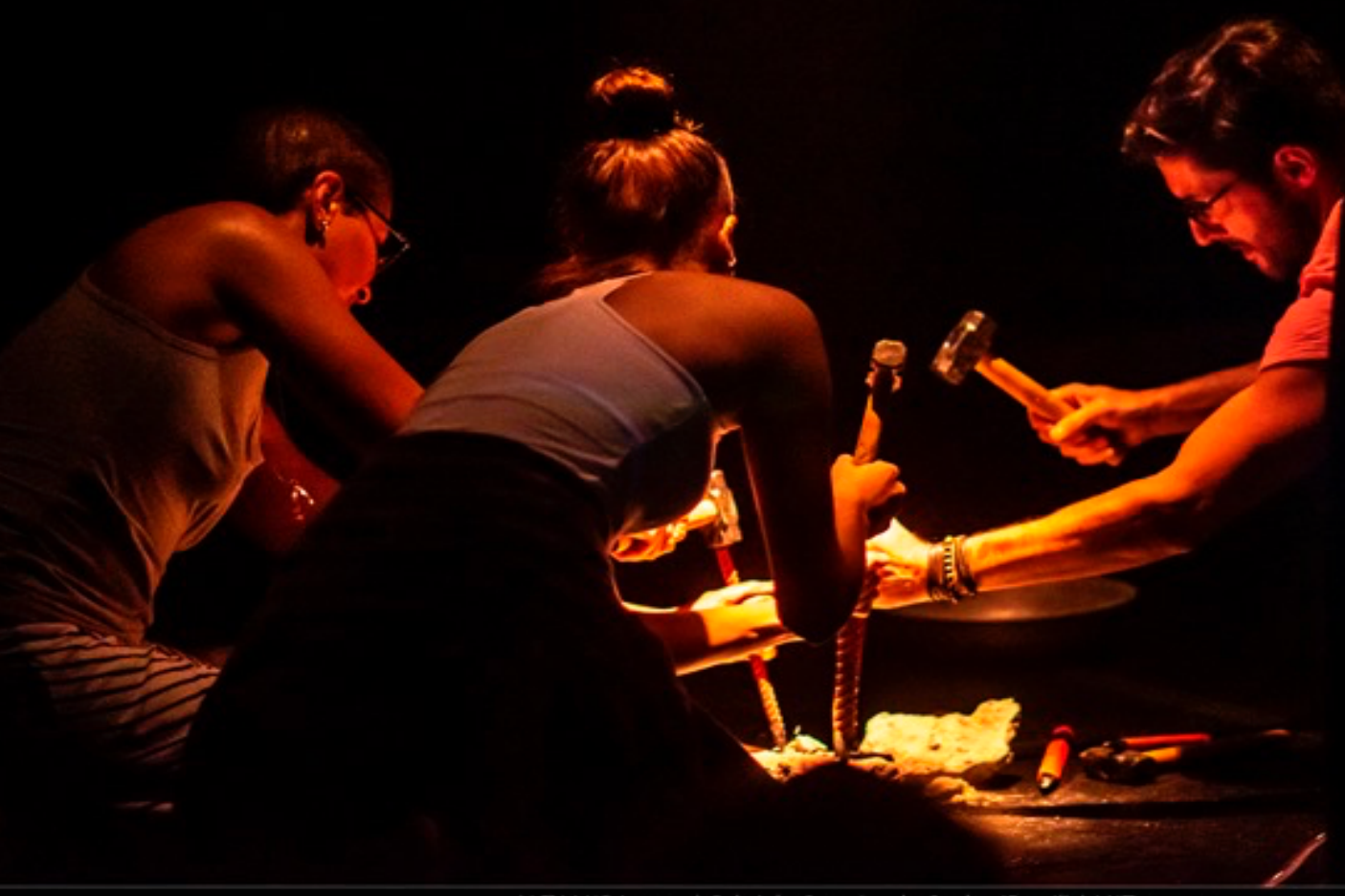




\section{Referências}

Brum, Eliane, Eduardo Viveiros de Castro e Deborah Danowski. Diálogos sobre o fim do mundo. El País Brasil, 29 de setembro de 2014. Disponível online em: https://brasil.elpais.com/brasil/2014/09/29/opinion/1412000283 365191.html.

Acesso em: 24 jan. 2020

Brum, Eliane. Dilma compôs seu réquiem em Belo Monte. El País Brasil, 15 de outubro de 2016. Disponível online em: https://brasil.elpais.com/brasil/2016/05/09/opinion/1462804348 582272.html Acesso em: 23 jan.2020

Chakrabarty, Dipesh. The Climate of History: Four Theses. Critical Inquiry, Vol. 35, No. 2, p. 197-222, 2009. The University of Chicago Press.

Cunha, Gabriela Carneiro. Rios. Fala pública na University Birkbeck. Manuscrito inédito.

Cunha, Gabriela Carneiro. Projeto Margens: Sobre Rios, Crocodilos e Vagalumes. Manuscrito inédito.

Cunha, Gabriela Carneiro. Programa Altamira 2042, 2018.

Danowski, Deborah e Eduardo Viveiros de Castro. Há Mundo Por Vir? Ensaio sobre os medos e os fins. Cultura e Barbárie: Instituto Socioambiental, 2014.

Haraway, Donna. Staying With The Trouble - Making Kin in the Chthulucene. London and Durham: Duke University Press, 2016.

Heidegger, Martin. The Question Concerning Technology and Other Essays. New York \& London: Garland Publishing, Inc., 1977.

Klein, Naomi. On Fire - The (Burning) Case for a New Deal. Simon \& Schuster, 2019. Krenak, Ailton. Ideias para adiar o fim do mundo. São Paulo: Companhia das Letras, 2020.

Kopenawa, Davi and Bruce Albert. A queda do céu - palavras de um xamã Yanomami. São Paulo: Companhia das Letras, 2010.

Patel, Raj and Jason W. Moore. A History of the World in Seven Cheap Things - A Guide to Capitalism, Nature, and the Future of the Planet. Oakland, CA: University of California Press, 2017. 
Plumwood, Valerie. Ecofeminist Analysis and the Culture of Ecological Denial. In: Lara Stevens, Peta Tait, Denise Varney (eds.), Feminist Ecologies - Changing Environments in the Anthropocene. Palgrave Macmillan, 2018, 97-112.

Viveiros de Castro, Eduardo. Estamos assistindo a uma ofensiva final. Entrevista a Agência Pública. El País Brasil, 10 de outubro de 2019. Disponível online em: https://brasil.elpais.com/brasil/2019/10/11/politica/1570796332 223092.html?rel=a rc articulo\#1579826754728 Acesso em: 12 set.2019

Viveiros de Castro, Eduardo. Metafísicas Canibais - elementos para uma antropologia pós-estrutural. São Paulo: Cosac Naify, N-1 Edições, 2015. e-Book.

Recebido em: 22/09/2021

Aprovado em: 09/10/2021 